\title{
Meeting Sustainability Requirements for SRC Bioenergy: Usefulness of Existing Tools, Responsibilities of Involved Stakeholders, and Recommendations for Further Developments
}

\author{
Oskar Englund • Göran Berndes • Fredrik Fredrikson • \\ Ioannis Dimitriou
}

(C) Springer Science+Business Media, LLC 2012

\begin{abstract}
Short rotation coppice (SRC) is considered an important biomass supply option for meeting the European renewable energy targets. This paper presents an overview of existing and prospective sustainability requirements, Member State reporting obligations and parts of the methodology for calculating GHG emissions savings within the EU Renewable Energy Directive (RED), and shows how these RED-associated sustainability criteria may affect different stakeholders along SRC bioenergy supply chains. Existing and prospective tools are assessed on their usefulness in ensuring that SRC bioenergy is produced with sufficient consideration given to the RED-associated criteria. A sustainability framework is outlined that aims at (1) facilitating the development of SRC production systems that are attractive from the perspectives of all stakeholders, and (2) ensuring that the SRC production is RED eligible. Producer manuals, EIAs, and voluntary certification schemes can all be useful for
\end{abstract}

Electronic supplementary material The online version of this article (doi:10.1007/s12155-012-9217-z) contains supplementary material, which is available to authorized users.

O. Englund $(\bowtie) \cdot G$. Berndes

Division of Physical Resource Theory, Department of Energy

and Environment, Chalmers University of Technology,

41296 Gothenburg, Sweden

e-mail: oskar.englund@chalmers.se

\section{F. Fredrikson}

County Administrative Board of Västra Götaland,

Department of Rural Development,

BOX 496, 50313 Borås, Sweden

\section{Dimitriou}

Department of Crop Production Ecology,

Swedish University of Agricultural Sciences (SLU),

P.O. Box 7016, 75007 Uppsala, Sweden ensuring RED eligibility. However, they are currently not sufficiently comprehensive, neither individually nor combined, and suggestions for how they can be more complementary are given. Geographical information systems offer opportunities for administrative authorities to provide stakeholders with maps or databases over areas/fields suitable for RED-eligible SRC cultivation. However, proper consideration of all relevant aspects requires that all stakeholders in the SRC supply chain become engaged in the development of SRC production systems and that a landscape perspective is used.

Keywords Short rotation coppice - EU · Producer manuals · EIA · Certification schemes · GIS

\section{Background}

Bioenergy has been put forward as a potential option for improving energy security and mitigating climate change [1-3]. It offers a new market for farmers and bioenergy production has, particularly in developing countries, been proposed as a possible driver of rural development with capacity to improve energy access, increase employment, and stimulate productivity growth in agriculture. Over recent years, however, concerns have arisen regarding the true environmental, social, and economic viability of bioenergy systems, and the bioenergy sector has been put under pressure to verify the sustainability of its operations.

In response to concerns about unintended consequences of biomass production and use for energy, producers of biomass feedstock in the private sector, as well as governmental and non-governmental organizations, have taken 
initiatives to develop criteria and indicators for sustainable bioenergy supply chains, as a means for regulating the bioenergy sector. The sustainability certification schemes that are being developed or implemented by a variety of private and public organizations can be applicable for different feedstock production sectors (notably forest and agriculture sectors) and for different bioenergy products, ranging from relatively unprocessed forest and agriculture residues to electricity and refined fuels, such as ethanol and biodiesel. They can be applicable for entire supply chains or certain segments of a supply chain [4-7].

The heterogeneity of sustainability certification schemes, which are developed largely without coordination, might present a challenge for the stakeholders along the bioenergy supply chains that must comply with these systems to maintain market access or to comply with legislative mandates. Also, consumers who prefer to purchase certified sustainable bioenergy, and regulatory agencies and governments involved in enforcing sustainability standards, may find it difficult to manage a wide range of systems that use different criteria and indicators for the sustainability certification.

Stakeholders involved with bioenergy that is used within the European Union (EU) have to specifically consider the EU Renewable Energy Directive (RED), which mandates levels of renewable energy use within the EU and also includes a sustainability scheme for biofuels for transport as well as for bioliquids used in other sectors. It sets out criteria and provisions to ensure sustainable production and use of biofuels and bioliquids [8]. These, or similar, sustainability criteria may later be applied also for solid and gaseous biofuels; in its 2010 report on sustainability requirements for the use of solid and gaseous biomass sources in electricity, heating, and cooling, the European Commission (EC) did not propose legally binding requirements at the time, but recommended that "Member States that either have, or who introduce, national sustainability schemes for solid and gaseous biomass used in electricity, heating, and cooling, ensure that these in almost all respects are the same as those laid down in the EU RED" [9]. There is a desire to ensure greater consistency and avoid unwarranted discrimination in the use of raw materials. It can therefore be assumed that the differentiation between different types of bioenergy will be lessened in future revisions, making the RED sustainability requirements legally binding also for solid and gaseous biofuels. It should be noted that the existing sustainability requirements in RED are limited compared to most certification standards and relates only to GHG emissions and biodiversity.

Short rotation coppice (SRC) (e.g., willow or poplar) is considered an important biomass supply option for meeting the European renewable energy targets [10]. A rapid expansion of SRC, especially in agricultural areas near the end user of biomass (e.g., heat and electricity plants for direct biomass combustion), is expected in several European countries [11]. It is important to note that cultivation of SRC, although using tree species, is an agricultural practice. It should therefore be regulated through the EU-wide Common Agricultural Policy (CAP), which cross-compliance requirements include considerations on, e.g., preservation of habitats, biodiversity, water management and use, and mitigation of climate change. ${ }^{1}$

Despite the similarities in management practices between SRC cultivation and conventional crop production, there are two principal differences; SRC plants are perennial and the species cultivated are trees. Consequently, there are several differences in how the cultivation affects the biophysical environment. Results from experiments reported in this special issue suggest that water quality in terms of $\mathrm{N}$ concentration in the groundwater is significantly improved when SRC is cultivated instead of cereals, but similar positive effects in terms of $\mathrm{P}$ are not evident [12]. However, Baum et al. [13] reports that less erosion is to be expected when SRC is cultivated instead of other arable crops, which probably leads to less P losses associated with surface runoff. Moreover, Dimitriou et al. [12] compared total carbon content and trace elements in the soil of a number of long-term commercial willow SRC fields in Sweden with adjacent, conventionally managed arable fields. Results showed that total carbon concentrations in the topsoil and subsoil of SRC fields were significantly higher $(9.4 \%)$ than in the respective reference fields. The respective average relative increase when SRC was compared with cereals was $10.5 \%$ in the topsoil and $26 \%$ in the subsoil, respectively. Regarding concentration of cadmium (Cd), an average relative reduction of $12 \%$ in the topsoil of SRC compared to cereals was found. Sewage sludge, which is commonly applied to SRC fields for nutrient recycling and additional compensation to the farmers, had no effect on the evaluated soil quality parameters. Concerning phytodiversity, positive impacts from SRC plantations can be expected with regards to species richness [14], and concerning zoodiversity and breeding birds abundance in particular, positive or negative impacts seem to be site and SRC-age specific [15].

The establishment of SRC plantations not only affects criteria of sustainability found in the RED scheme, but also the agricultural landscape as such. As discussed later in this paper, a wide range of stakeholders are either affected by, or expected to influence, the establishment of SRC plantations. Proper consideration of all relevant aspects therefore requires that all stakeholders in the SRC supply chain are engaged in the development of SRC production systems and that a landscape perspective is used. A multi-stakeholder landscape level process would facilitate linking with the

\footnotetext{
${ }^{1}$ Forest management is regulated on a national level, with policy guidance through the EU Forestry Strategy and international processes such as the Ministerial Conference for the Protection of Forests in Europe.
} 
European Landscape Convention (ELC), which promotes the protection, management, and planning of European landscapes and organizes European cooperation on landscape issues. The ELC also promotes the public involvement in matters concerning the landscape. It is the first international treaty to be exclusively concerned with all dimensions of European landscapes [16].

This paper presents an overview of existing and prospective sustainability requirements as well as of Member State (MS) reporting obligations in the EU RED, and shows how these RED-associated criteria may affect different stakeholders along the SRC bioenergy supply chain-from feedstock producers to energy consumers. Based on this, the extent to which three different types of tools (producer manuals, environmental impact assessments, and sustainability certification schemes) can be used to ensure that SRC bioenergy is produced with sufficient consideration given to RED-associated criteria is discussed. In a concluding section, a framework for engaging relevant stakeholders in the development of SRC within a landscape perspective is outlined. This framework has two purposes: (1) to facilitate the development of SRC production systems that are attractive from the perspectives of all stakeholders; and (2) to ensure that the SRC production is RED eligible.

\section{Methodology}

\section{Analysis of RED}

As stated earlier in this paper, stakeholders involved in production of solid and gaseous biofuels that are used within the EU have good reasons to consider RED sustainability requirements, despite the fact that they are currently only legally binding for bioliquids. It is also indicated in RED that additional legally binding sustainability requirements might be added in future revisions of the directive. For example, Article 18(9b) in RED states: "By 31 December 2012, the Commission shall report to the European Parliament and to the Council on whether it is feasible and appropriate to introduce mandatory requirements in relation to air, soil, or water protection". Identifying and considering such "potential requirements" in the development of sustainability frameworks reduces the risk of having to make future adjustments.

Besides the sustainability requirements for production of bioliquids, RED requires the EC and MS to monitor and report on certain sustainability aspects of bioenergy production and use. Such obligations typically concern impacts due to production and use of bioenergy in general, i.e., no distinctions are made between liquid, solid, or gaseous biofuels. Therefore, in order to fulfill the obligations in RED, sustainability aspects related to monitoring and reporting need to be addressed for SRC. Furthermore, specific sustainability considerations can be identified in the methodology for calculating GHG emissions savings. Considering these in a sustainability framework for SRC bioenergy would support the involved stakeholders in producing bioenergy with high GHG emissions savings. Finally, RED includes a number of sustainability considerations requiring no particular actions at present. Such considerations should be noted, as they may be subject to reporting and monitoring obligations in the future, or even become additional sustainability requirements.

The RED was reviewed using the above reasoning and RED-associated sustainability criteria were formulated. The criteria were then sorted under specific categories to put them into a correct context (see also Englund et al. [17] and Electronic Supplementary Material (ESM) 1). Finally, the criteria were evaluated on their relevance for SRC bioenergy on a national level.

\section{Inventory and Categorization of Stakeholder Landscape}

The stakeholder landscape was investigated using in-house experience and stakeholder consultation, to identify principal stakeholders involved in SRC bioenergy. A general SRC bioenergy supply chain was created and the stakeholders' roles in meeting RED-associated criteria were discussed.

\section{Analysis of Producer Manuals}

Ten producer manuals were collected and analyzed. The manuals all refer to willow and/or poplar coppice production, including site selection, planting, and harvesting. The REDassociated criteria can be both directly and indirectly covered in producer manuals and also at varying level of comprehensiveness; for each criterion, manuals were assigned as having major, minor, or no coverage. Based on the number of producer manuals that cover each criterion - and the extent (minor or major) of coverage - the overall coverage of producer manuals was determined.

\section{Analysis of Environmental Impact Assessments}

Nineteen EIAs were collected from bioenergy projects that include the establishment of plantations or large-scale agricultural operations, and/or construction of a biofuel processing plant.

Four approaches were used to collect EIAs: (1) email inquiries to researchers and experts; (2) email inquiries to EIA consultants, certification audit companies, and development banks; (3) internet searches; and (4) asking local consultants associated to Winrock International in 18 countries to "attach any Environmental Impact Assessments (EIAs), Strategic Environmental Assessments (SEAs), or Social Impact Assessments (SIAs) you encounter related to biofuels". 
Depending on the nature of the assessed bioenergy projects, EIAs were sorted into three categories: Plantations, Biofuel plant, and Plantations and biofuel plant. The EIAs were then assessed on their coverage in relation to the RED-associated criteria. For each criterion, an EIA was assigned one of five levels of coverage, depending on how the criterion was considered in the EIA. These individual results were then combined to indicate the coverage of RED-associated criteria in EIAs in general. Coverage levels include: overall low coverage; varying coverage; and overall high coverage. ${ }^{2}$

\section{Sustainability Certification Schemes}

An overviewing review of international sustainability certification schemes relevant for SRC bioenergy was performed. Based on this, the role of certification in national SRC bioenergy sustainability frameworks was discussed.

\section{Results}

RED-Associated Sustainability Criteria Relevant for SRC and Corresponding Responsibilities for Principal Stakeholders

Thirty-one sustainability criteria were derived from RED. These include the described existing and prospective sustainability requirements, reporting and monitoring obligations for the EC and MS, and more general sustainability considerations. On a national level, 18 of these 31 criteria are relevant for national SRC bioenergy sustainability schemes to address (Table 1, see also ESM 1 for more details). These criteria are related to:

1. Existing and prospective legally binding sustainability requirements,

2. Reporting obligations for MS, and

3. The methodology for calculating GHG emissions savings.

Throughout this paper, the term "RED-associated sustainability criteria", "RED-associated criteria", "RED criteria", or "criteria" refer to the criteria presented in Table 1. "Existing RED sustainability requirements" or "RED requirements" refer to the existing, legally binding, sustainability requirements for bioliquids laid out the RED.

Principal stakeholders involved in producing SRC bioenergy include landowners, entrepreneurs, bioenergy producers, end users, administrators, and legislators. These are defined in Table 2.

\footnotetext{
${ }^{2}$ See also Englund et al. [17] for more information.
}

The principal stakeholders are involved at different stages in the SRC bioenergy supply chain (Fig. 1). Planting may be undertaken by the landowner or, more commonly, by an entrepreneur. Cultivation is most often the responsibility of the landowner. Harvesting is typically done by an entrepreneur but can also be done by the landowner. Transportation of the harvested biomass can be done by either the landowner, an entrepreneur, or the bioenergy producer. Processing of the biomass into bioenergy for sale on a market is done by the bioenergy producer. Finally, the bioenergy use stage involves end users. In addition, administrators and legislators are in different ways involved in regulating each stakeholder in each stage of the supply chain. Therefore, specific SRC bioenergy supply chains can have different structures depending on which stakeholders are involved at the different stages.

The bioenergy producer is responsible for demonstrating compliance with the legally binding RED sustainability requirements and for calculating specific GHG emissions savings (if not using default values). The legislator on the other hand is responsible for meeting the MS reporting obligations. Even so, the RED-associated criteria apply at all stages in the supply chain, except at the final stage where the bioenergy is being used (Fig. 1). This means that all stakeholders besides the end user can be responsible for ensuring that the criteria are considered, depending on the specific structure of a supply chain. It is therefore difficult to assign stakeholder-specific responsibility for the individual criteria, implying that all criteria should be communicated to all stakeholders. In addition, effective consideration of some criteria may require interactions between several stakeholders depending on their respective involvement along the SRC bioenergy supply chain. Providing opportunities for such interactions may be a challenge, since experiences from Sweden show that coordination between different stakeholders involved with SRC can be poor [18] (see Fig. 2, fact box). It is therefore important that a sustainability framework is designed so as to facilitate stakeholder interaction to clarify the stakeholders' respective roles and responsibilities and to identify points where conflicts of interests may arise and where there are tradeoffs to be made between partly non-compatible goals and objectives.

Another important key to a successful sustainability framework is to provide the involved stakeholders with guidance on how to produce SRC bioenergy in compliance with the REDassociated criteria. In addition, there is a need for tools to provide verification and continuous monitoring of the RED eligibility. This is addressed in the following chapter.

\section{Potentially Useful Tools for National SRC Bioenergy Sustainability Schemes}

Producer manuals, environmental impact assessments (EIAs), and certification schemes can all provide guidance as well as contribute to the monitoring and verification of sustainable 
Table 1 RED sustainability categories and associated sustainability criteria of national relevance for SRC bioenergy production

\begin{tabular}{lll}
\hline RED categories & Associated sustainability criteria & Current status \\
\hline Biodiversity & 1.1 Preservation of natural forests & Existing requirement \\
& $\begin{array}{l}\text { 1.2 Preservation of areas designated for nature protection purposes } \\
\text { or for the protection of rare, threatened, and endangered species }\end{array}$ & Existing requirement \\
& 1.3 Preservation of highly biodiverse grasslands & Existing requirement \\
& 1.4 Impacts on biodiversity & MS reporting obligation \\
& 2.1 Preservation of peatlands & Existing requirement \\
& 2.2 GHG emissions from extraction or cultivation of raw materials & GHG emissions savings calculation \\
& 2.3 GHG emissions from processing & GHG emissions savings calculation \\
& 2.4 GHG emissions from transport and distribution & GHG emissions savings calculation \\
& 2.5 Carbon capture and replacement & GHG emissions savings calculation \\
& 2.6 Co-generation of electricity, if producing bioliquids & GHG emissions savings calculation \\
& 3.1 Preservation of wetlands & Existing requirement \\
& 3.2 Preservation of continuously forested areas & Existing requirement \\
& 3.3 Restoration of degraded land & GHG emissions savings calculation \\
& 3.4 Restoration of contaminated land & GHG emissions savings calculation \\
Air, water and soil & 4.1 Impacts on air quality & MS reporting obligation/prospective requirement \\
& 4.2 Impacts on water quality & MS reporting obligation/prospective requirement \\
& 4.3 Impacts on water availability & MS reporting obligation/prospective requirement \\
& 4.4 Impacts on soil quality & MS reporting obligation/prospective requirement
\end{tabular}

biomass production. In order to determine whether these tools, individually or combined, can be useful for ensuring that SRC bioenergy is produced with sufficient consideration given to the RED-associated criteria, they have been assessed on their coverage in relation to the criteria in Table 1.

\section{Producer Manuals}

The purpose of producer manuals is to provide guidelines to support good management practices. In the case of SRC, manuals typically cover the feedstock production phase but can also cover other parts of the supply chain, e.g., transportation of harvested biomass, processing, etc. Ten producer manuals were assessed on their coverage of RED-associated criteria (Table 3). All manuals refer to willow and/or poplar coppice production, including site selection, planting, and harvesting. Most of the manuals also consider transportation and handling/storage of harvested material, but only three manuals cover the processing of biomass for bioenergy (i.e., heat, electricity, and bioliquids).

The general usefulness of producer manuals for ensuring that SRC bioenergy is produced with sufficient consideration given to the RED is assumed to coincide with their overall coverage of the specific RED-associated criteria. Given this connection, Table 3 can be interpreted as follows: Manuals are likely to be useful for ensuring avoidance of SRC production on peatlands and wetlands, as well as impacts on soil quality. Manuals are potentially useful for ensuring that impacts on air and water quality, water availability, and biodiversity, are avoided/acceptably low. They are also potentially useful for considering GHG emissions from cultivation, extraction, transport and distribution, and for avoiding SRC production on protected areas, i.e., areas designated for nature protection purposes or for the protection of rare, threatened, and endangered species. Manuals are however unlikely to be useful for ensuring that the remaining eight RED-associated criteria (i.e.,
Table 2 Principal stakeholders involved in SRC bioenergy supply chains

\begin{tabular}{ll}
\hline Stakeholders & Interpretation \\
\hline Landowner & Farmer producing SRC \\
Entrepreneur & Responsible for planting/harvesting/transport (can be several entrepreneurs) \\
Bioenergy producer & Producer of electricity/heat/biofuels \\
End user & Consumer of electricity/heat/biofuels \\
Administrator & Municipality, county administrative board \\
Legislator & National government, European Commission, other bodies involved in \\
& developing sustainability frameworks (e.g., certification systems) \\
\hline
\end{tabular}


Fig. 1 A typical SRC

bioenergy supply chain, with indication of involvement of principal stakeholders in the different supply chain segments
Involved stakeholders

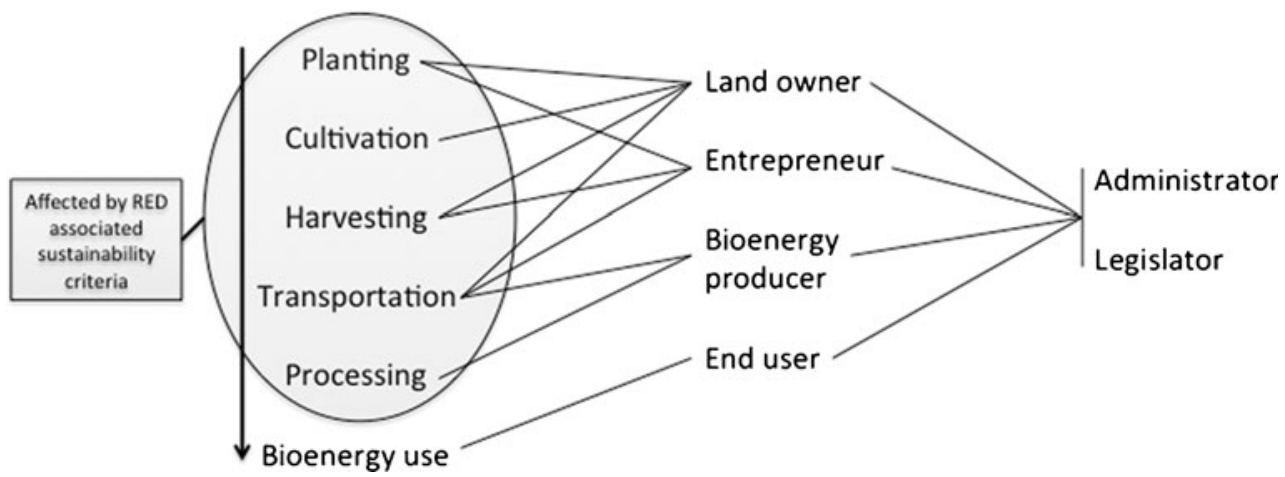

criteria $1.1,1.3,2.3,2.5,2.6,3.2,3.3,3.4)$ are sufficiently considered.

The fact that the assessed manuals poorly cover eight of the 18 RED-associated criteria does not mean that SRC producers will automatically disregard these. For example: even though it is seldom discussed in manuals, SRC producers are less likely to convert forests into SRC plantations. Given that manuals typically describe only how to prepare existing cropland or grassland for SRC planting, it can be implicit that recently deforested land is unsuitable for SRC establishments. Even so, to make sure that the RED sustainability requirement of no deforestation is complied with, producer manuals should be complemented with the requirement that forested areas should not be converted to SRC plantations. This reasoning (i.e., not to exclude seemingly unnecessary information) should be applied when it comes to all RED-associated criteria, in order to safeguard that they are all considered.

The assessment shows that existing producer manuals are not sufficient for ensuring that SRC bioenergy is produced with sufficient consideration given to the RED-associated criteria. However, as manuals are typically consulted before starting new establishments and as they are commonly known and widely used by SRC and bioenergy producers, they could potentially be further developed to fulfill this purpose. It should however be taken into account that producers might not fully follow manuals. In such a case, it is of little use that the manual itself is perfectly comprehensive; the biomass might still not be RED eligible. Therefore, it should be clear which information in the manual refers to good management practice in general and which are connected to RED-associated criteria, so that the producers understand the consequences when deviating from the different advices given.

Even if SRC bioenergy is produced in compliance with future sustainability requirements, it would not automatically make it RED eligible, as compliance with the requirements has to be demonstrated. Therefore, advice on how the producers should monitor their activities in order to demonstrate compliance should also be provided in the manuals. The assessed manuals typically do not include such advice.
Environmental Impact Assessments

An EIA can be defined as "the process of identifying, predicting, evaluating, and mitigating biophysical, social, and other relevant effects of development proposals prior to major decisions being taken and commitments made" $[19,20]$. Thus, the main purpose of an EIA is to help incorporate environmental considerations in decision making. This is achieved primarily by assembling and analyzing information, identifying potential environmental impacts from specific development proposals, and proposing measures to avoid or mitigate these impacts. An EIA for a proposed project should be conducted before major decisions are taken. In this sense, environmental considerations in an EIA can influence the whole decisionmaking process, from initial contemplation of a project to actual implementation [21].

The concept of "environment" in EIA originates from the initial focus on the biophysical environment, but has over time often been extended to include also physical-chemical, biological, visual, cultural, and socio-economic components of the total environment [20]. EIA systems may therefore use different definitions of the concept "environment", including biophysical aspects only or also social, economic, and institutional aspects.

Typically, an EIA is made at a stage where projects are subject to consideration by authorities, but the EIA may also be used in earlier feasibility studies to guide decisions about how to proceed with a certain project idea. One example can be when stakeholders want to investigate whether a planned bioenergy project will have prospects for targeting the RED market [17]. Thus, besides serving a legal and institutional procedure, EIAs can also help stakeholders avoid or mitigate impacts from planned actions or unplanned events, e.g., natural disasters [20]. Specifically for the EU RED market, an advantage of using EIAs is that it can provide information needed to demonstrate that the produced biomass is RED eligible [17].

Table 4 shows the usefulness of 19 EIAs for this purpose (see also [17]). These EIAs relate to plantation projects or biofuel projects that either include both biofuel production 


\section{Administrative authorities involved in SRC production in Sweden}

Profitable SRC production is currently taking place almost entirely on farmland and is therefore under the sectorial responsibility of the Board of Agriculture when it comes to rules for agricultural management, establishment support etc. Being a potential energy crop, research and other activities advancing SRC production for energy are supported by the Energy Agency.. Production of SRC on farmland affects the environmental quality goals, primarily governed by the Environmental Protection Agency. Production of perennial crops affects the landscape and the cultural environment, for which the National Heritage Board has the main responsibility. Even though SRC production on farmland is not directly the responsibility of the Forest Agency, the products (i.e. forest fuels) are. The Forest Agency (and other actors) offers the establishment of a green plan for forest holdings, which can be used as a basis for FSC and PEFC certification, although this system is currently only relevant for forest management and not SRC production on farmland. From the perspective of business administration, as well as recycling considerations it can be beneficial to use multifunctional production systems, for instance where it is possible to take advantage of the effective uptake of nutrients and heavy metals in fast growing trees. If SRC production is used for restoring contaminated land or the disposal of sewage sludge, the Board of Housing, Building and Planning, the Chemical Agency, the Board of Health and Welfare and the Institute for Communicable Disease Control all become involved. Finally there are aspects of e.g. nature, culture, agriculture and healthcare that require that County Administrative Boards and Municipalities become involved.

Thus, a large number of authorities at national, county and municipal levels have influence on SRC production. The coordination between different authorities' interests is poor. In addition, questions regarding the use of sewage sludge and ash in SRC production are sometimes circulated within authorities without anyone taking a clear overall responsibility. This can seriously hamper the process and there is also a risk of power struggles between authorities. In such situations, the holistic perspective gets lost and synergies between objectives are not realized.

Fig. 2 Fact box. Administrative authorities involved in SRC production in Sweden [18]

plants and plantations for feedstock supply or only the biofuel production plants. None of the 19 EIAs relate to $\mathrm{SRC}$ projects in EU, since EIAs are typically not required for SRC production.

As seen in Table 4, there are in many cases large variations in coverage between the individual EIA reports. Of the 18 RED-associated criteria, nine were considered in a sufficiently similar way in the EIAs to allow the general coverage to be estimated with an adequate accuracy. Of these nine criteria, five were typically well covered by the EIAs (impacts on biodiversity, impacts on air quality, impacts on water quality, impacts on water availability, and impacts on soil quality), while four were typically poorly covered (GHG emissions from extraction or cultivation of raw materials, GHG emissions from transport and distribution, restoration of degraded land and restoration of contaminated land).
Notable differences can be seen also between the project categories; EIAs for biofuel projects that include plantations for the feedstock supply had better coverage than EIAs for only plantations (that naturally do not consider criteria related to post harvest activities) or for biofuel projects that import their feedstock from external sources and therefore do not consider the feedstock production phase. This indicates that the entire supply-chain needs to be considered in EIA in order to ensure full coverage of the RED-associated criteria and consequently RED eligibility.

Only five RED-associated criteria are "highly covered" by the assessed EIAs, indicating that a typical EIA does not suffice for ensuring RED eligibility of a planned bioenergy project. However, if EIAs were extended to sufficiently consider all criteria, it should be possible to use it for assessing RED eligibility. One problem can be that such 
Table 3 Coverage of 10 producer manuals in relation to the RED-associated criteria

\begin{tabular}{|c|c|c|c|c|}
\hline \multirow[t]{2}{*}{ RED category } & \multirow[t]{2}{*}{ Associated sustainability criteria } & \multicolumn{3}{|c|}{ Coverage of producer manuals } \\
\hline & & $\begin{array}{l}\text { Minor } \\
\text { coverage }\end{array}$ & $\begin{array}{l}\text { Major } \\
\text { coverage }\end{array}$ & $\begin{array}{l}\text { Overall } \\
\text { coverage }^{\mathrm{a}}\end{array}$ \\
\hline \multirow[t]{4}{*}{ Biodiversity } & 1.1 Preservation of natural forests & 0 & 3 & - \\
\hline & $\begin{array}{l}\text { 1.2 Preservation of areas designated for nature protection purposes } \\
\text { or for the protection of rare, threatened, and endangered species }\end{array}$ & 2 & 3 & $+/-$ \\
\hline & 1.3 Preservation of highly biodiverse grasslands & 0 & 2 & - \\
\hline & 1.4 Impacts on biodiversity & 3 & 4 & $+/-$ \\
\hline \multirow[t]{6}{*}{ GHG emissions } & 2.1 Preservation of peatlands & 6 & 3 & + \\
\hline & 2.2 GHG emissions from extraction or cultivation of raw materials & 7 & 2 & $+/-$ \\
\hline & $2.3 \mathrm{GHG}$ emissions from processing & 4 & 0 & - \\
\hline & 2.4 GHG emissions from transport and distribution & 3 & 4 & $+/-$ \\
\hline & 2.5 Carbon capture and replacement & 0 & 0 & - \\
\hline & 2.6 Co-generation of electricity, if producing bioliquids & 1 & 0 & - \\
\hline \multirow[t]{4}{*}{ Carbon stock } & 3.1 Preservation of wetlands & 3 & 6 & + \\
\hline & 3.2 Preservation of continuously forested areas & 1 & 2 & - \\
\hline & 3.3 Restoration of degraded land & 0 & 0 & - \\
\hline & 3.4 Restoration of contaminated land & 3 & 0 & - \\
\hline \multirow[t]{4}{*}{ Air, water and soil } & 4.1 Impacts on air quality & 1 & 3 & $+/-$ \\
\hline & 4.2 Impacts on water quality & 6 & 2 & $+/-$ \\
\hline & 4.3 Impacts on water availability & 4 & 2 & $+/-$ \\
\hline & 4.4 Impacts on soil quality & 4 & 6 & + \\
\hline
\end{tabular}

${ }^{\text {a }}$ Coverage index $(0-5)$ calculated with: (minor coverage $\times 0.5+$ major coverage)

Interpretation: $0-1.5=$ low coverage $(-), 1.6-2.9=$ varying coverage $(+/-), 3-5=$ high coverage $(+)$

EIAs may be too costly for smaller projects such as farm level SRC production. Thus, it would be required that EIAs are streamlined to become less time consuming and expensive.

\section{Voluntary Certification Schemes}

Several schemes exist for certification of sustainable production of biomass or biomass products, including bioenergy. Certification schemes require producers to comply with a set of sustainability criteria in order to become certified. In addition, certifiers require that producers monitor and document their operations to allow demonstration of compliance with the criteria. In cases where a product is certified (e.g., bioenergy), the full supply chain typically needs to be considered. Often, guidelines are provided in order to help producers to adjust their operations.

The second subparagraph of Article 18(4) in the RED [8] states that:

"The Commission may decide that voluntary national or international schemes setting standards for the production of biomass products contain accurate data for the purposes of Article $17(2)^{3}$ or demonstrate that consignments of biofuel comply with the sustainability criteria set out in Article 17(3) to (5). ${ }^{4}$ The Commission may decide that those schemes contain accurate data for the purposes of information on measures taken for the conservation of areas that provide, in critical situations, basic ecosystem services (such as watershed protection and erosion control), for soil, water, and air protection, ${ }^{5}$ the restoration of degraded land, ${ }^{6}$ the avoidance of excessive water consumption in areas where water is scarce $^{7}$ and on the issues referred to in the second subparagraph of Article 17(7)."

The above citation from the RED refers to 22 of the 28 RED-associated criteria in [17] and to 16 of the 18 criteria identified in this paper as relevant for national sustainability frameworks (see footnotes 3-7). The Commission has thus acknowledged that certification schemes can play a role in

\footnotetext{
$\overline{{ }^{3} \text { Refers to RED }}$ criteria $2.2-6$

${ }^{4}$ Refers to RED criteria $1.1-3,2.1,3.1-2$

${ }^{5}$ Refers to RED criteria 4.1-2, 4.4

${ }^{6}$ Refers to RED criterion 3.3

${ }^{7}$ Refers to RED criterion 4.3
} 
Table 4 Coverage of 19 EIAs for bioenergy projects in relation to the RED-associated criteria

\begin{tabular}{|c|c|c|c|c|c|}
\hline \multirow[t]{2}{*}{ RED category } & \multirow[t]{2}{*}{ Associated sustainability criteria } & \multicolumn{4}{|c|}{ Coverage of EIAs ${ }^{\mathrm{a}, \mathrm{b}}$} \\
\hline & & Plantations & $\begin{array}{l}\text { Biofuel } \\
\text { plant }\end{array}$ & $\begin{array}{l}\text { Plantations and } \\
\text { biofuel plant }\end{array}$ & $\begin{array}{l}\text { Overall } \\
\text { coverage }\end{array}$ \\
\hline \multirow[t]{4}{*}{ Biodiversity } & 1.1 Preservation of natural forests & + & - & + & $+/-$ \\
\hline & $\begin{array}{l}\text { 1.2 Preservation of areas designated for nature protection purposes } \\
\text { or for the protection of rare, threatened, and endangered species }\end{array}$ & $+/-$ & $+/-$ & $+/-$ & $+/-$ \\
\hline & 1.3 Preservation of highly biodiverse grasslands & $+/-$ & $+/-$ & $+/-$ & $+/-$ \\
\hline & 1.4 Impacts on biodiversity & + & $+1-$ & + & + \\
\hline \multirow[t]{6}{*}{ GHG emissions } & 2.1 Preservation of peatlands & $+/-$ & - & $+/-$ & $+/-$ \\
\hline & $\begin{array}{l}\text { 2.2 GHG emissions from extraction or cultivation } \\
\text { of raw materials }\end{array}$ & - & - & $+/-$ & - \\
\hline & $2.3 \mathrm{GHG}$ emissions from processing & - & $+1-$ & $+/-$ & $+/-$ \\
\hline & 2.4 GHG emissions from transport and distribution & - & - & - & - \\
\hline & 2.5 Carbon capture and replacement & - & $+/-$ & $+/-$ & $+/-$ \\
\hline & $\begin{array}{l}\text { 2.6 Co-generation of electricity, if producing } \\
\text { bioliquids }\end{array}$ & - & - & + & $+/-$ \\
\hline \multirow[t]{4}{*}{ Carbon stock } & 3.1 Preservation of wetlands & $+/-$ & - & $+/-$ & $+/-$ \\
\hline & 3.2 Preservation of continuously forested areas & $+/-$ & - & + & $+/-$ \\
\hline & 3.3 Restoration of degraded land & - & - & $+/-$ & - \\
\hline & 3.4 Restoration of contaminated land & - & - & - & - \\
\hline \multirow[t]{4}{*}{ Air, water and soil } & 4.1 Impacts on air quality & $+/-$ & + & + & + \\
\hline & 4.2 Impacts on water quality & + & + & + & + \\
\hline & 4.3 Impacts on water availability & + & $+1-$ & + & + \\
\hline & 4.4 Impacts on soil quality & + & $+1-$ & + & + \\
\hline
\end{tabular}

${ }^{a}$ Interpretation: Overall low coverage (-), varying coverage $(+/-)$, overall high coverage $(+)$.

${ }^{\mathrm{b}}$ See also [17].

verifying that biofuel projects comply with existing and also possible future RED requirements. The EC has to date approved seven schemes for the purpose of verifying that bioliquids are produced in compliance with the existing RED requirements [22] (Table 5). Additional schemes are likely to be added as the benchmarking continues and rejected schemes reapply with revised standards.

Four out of seven RED-approved certification schemes can be relevant for SRC production; ISCC, RSB, 2BSvs, and RBSA. These schemes were assessed on their coverage in relation to the existing RED sustainability requirements only (all schemes also provide for calculation of GHG emissions savings). The extent to which they cover the RED-associated criteria related to reporting obligations has not been investigated. It should be noted that these schemes mainly focus on the production of liquid biofuels

The approved certification schemes represent an option for ensuring RED eligibility. However, as the approved schemes only have been proven to sufficiently cover the existing RED requirements, certification by an approved scheme may not ensure future RED eligibility. Other schemes may cover the RED-associated criteria equally well or better, although being better suited for SRC production in general or for specific local conditions. Information about which certification schemes have applied for, or shown an interest in, RED approval is unfortunately not available at present $[23,24]$. It is therefore advised that separate assessments are initiated in parallel to the EC benchmark process, to clarify which specific schemes are best suited for verifying RED eligibility of SRC bioenergy production. Such assessments should include, but not be limited to, the RED-approved schemes and carefully monitor new outcomes from the EC benchmark process.

Examples of voluntary certification schemes potentially relevant for the entire, or parts of, the SRC bioenergy supply chain are presented in Table 6 . These may or may not apply for RED approval and are likely to have varying coverage of the RED-associated criteria.

Tables 5 and 6 may give the impression that SRC bioenergy stakeholders interested in certification have a variety of options. However, in several cases it is uncertain if the schemes are suitable for, or even accept, SRC production. Even though SRC cultivation clearly has more in common with conventional agriculture than forest management, it is not clear whether schemes for certification of sustainable agricultural management (e.g., EU organic farming, 
Table 5 Voluntary certification schemes approved by the EC for verifying that biofuels and -feedstock is produced in compliance with RED sustainability requirements

\begin{tabular}{|c|c|c|c|}
\hline \multicolumn{2}{|l|}{ Certification scheme } & \multirow{2}{*}{$\begin{array}{l}\begin{array}{l}\text { Geographical } \\
\text { coverage }\end{array} \\
\text { Global }\end{array}$} & \multirow{2}{*}{$\begin{array}{l}\text { Relevant for SRC } \\
\text { Yes, covers all types of feedstock }\end{array}$} \\
\hline $\begin{array}{l}\text { International Sustainability and Carbon } \\
\text { Certification (ISCC) }\end{array}$ & www.iscc-system.org & & \\
\hline Bonsucro EU production standard & www.bonsucro.com & Global & No, only sugarcane \\
\hline $\begin{array}{l}\text { Roundtable on Responsible Soy } \\
\text { (RTRS) (EU RED standard) }\end{array}$ & www.responsiblesoy.org & Global & No, only soybean \\
\hline Roundtable on Sustainable Biofuels (RSB) & http://rsb.epfl.ch & Global & Yes, covers all types of feedstock \\
\hline Biomass Biofuels voluntary scheme (2BSvs) & http://en.2bsvs.org & Global & Yes, covers all types of feedstock \\
\hline $\begin{array}{l}\text { Abengoa RED Bioenergy Sustainability } \\
\text { Assurance (RBSA) }\end{array}$ & www.abengoa.com/corp/web/en & Global & Yes, covers all types of feedstock \\
\hline $\begin{array}{l}\text { Greenergy Brazilian Bioethanol } \\
\text { verification programme }\end{array}$ & www.greenergy.com & Brazil & No, only sugarcane \\
\hline
\end{tabular}

GLOBALGAP, etc.) will accept to certify SRC; in fact, no such examples have been found. However, certification schemes for sustainable forest management have been identified as potentially accepting SRC plantations [25]. The ambiguity of SRC production (i.e., trees are cultivated with management practices similar to conventional agriculture) brings difficulties in evaluating whether or not a certification scheme is relevant for SRC or not, unless it is specified in the certification standards. Also, since some certification schemes (e.g., FSC and PEFC) have national variants of their certification standards, their relevance for SRC is likely to differ between countries. Therefore, national sustainability frameworks for SRC need to be designed so that the stakeholders can judge what certification options are available. As a consequence of nationally differing certification standards, it is difficult to provide a useful internationally valid assessment of the coverage of certain certification schemes in relation to the RED-associated criteria. Therefore, such assessments also need to be done on a country level within the SRC sustainability framework.

\section{Conclusions and Discussion}

Eighteen sustainability criteria associated to EU RED have been identified as relevant for stakeholders involved in SRC bioenergy (Table 1). These are related to (1) existing and prospective legally binding sustainability requirements, (2) reporting obligations for MS, and (3) the methodology for calculating GHG emissions savings. Even though specific stakeholders can be officially responsible for demonstrating compliance with certain RED-associated criteria, other

Table 6 Examples of voluntary certification schemes potentially relevant for the entire, or parts of, the SRC bioenergy supply chain

\begin{tabular}{|c|c|c|c|}
\hline \multicolumn{2}{|l|}{ Certification scheme } & \multirow{2}{*}{$\begin{array}{l}\text { Type of feedstock } \\
\text { Forest based }\end{array}$} & \multirow{2}{*}{$\begin{array}{l}\text { Coverage } \\
\text { Biomass production, globa }\end{array}$} \\
\hline Forest Stewardship Council (FSC) & www.fsc.org & & \\
\hline $\begin{array}{l}\text { Programme for the Endorsement } \\
\text { of Forest Certification (PEFC) }\end{array}$ & www.pefc.org & Forest based & Biomass production, global \\
\hline REDcert & www.redcert.org/index.php?lang=en & Not defined & $\begin{array}{l}\text { Bioliquids, Germany (also } \\
\text { other European countries) }\end{array}$ \\
\hline NTA 8080 & www.sustainable-biomass.org & Forest and agriculture based & $\begin{array}{l}\text { Bioliquids/heat/ } \\
\text { electricity, global }\end{array}$ \\
\hline $\begin{array}{l}\text { International Organization } \\
\text { for Standardization (ISO) }\end{array}$ & $\begin{array}{l}\text { www.iso.org/iso/home.htm } \\
\text { (standard under development) }\end{array}$ & Forest and agriculture based & $\begin{array}{l}\text { Bioliquids/heat/ } \\
\text { electricity, global }\end{array}$ \\
\hline Green Gold Label (GGL) & www.greengoldcertified.org/site/pagina.php? & Forest and agriculture based & $\begin{array}{l}\text { Bioliquids/heat/ } \\
\text { electricity, global }\end{array}$ \\
\hline EKOenergy & www.ekoenergy.org & Forest and agriculture based & $\begin{array}{l}\text { Heat/electricity, Finland } \\
\text { (also Sweden, Norway, } \\
\text { and Denmark) }\end{array}$ \\
\hline Bra Miljöval & www.naturskyddsforeningen.se/bra-miljoval & Forest and agriculture based & $\begin{array}{l}\text { Heat/electricity, Sweden } \\
\text { (also other countries) }\end{array}$ \\
\hline Green-e & www.green-e.org & Forest and agriculture based & Electricity, USA \\
\hline
\end{tabular}




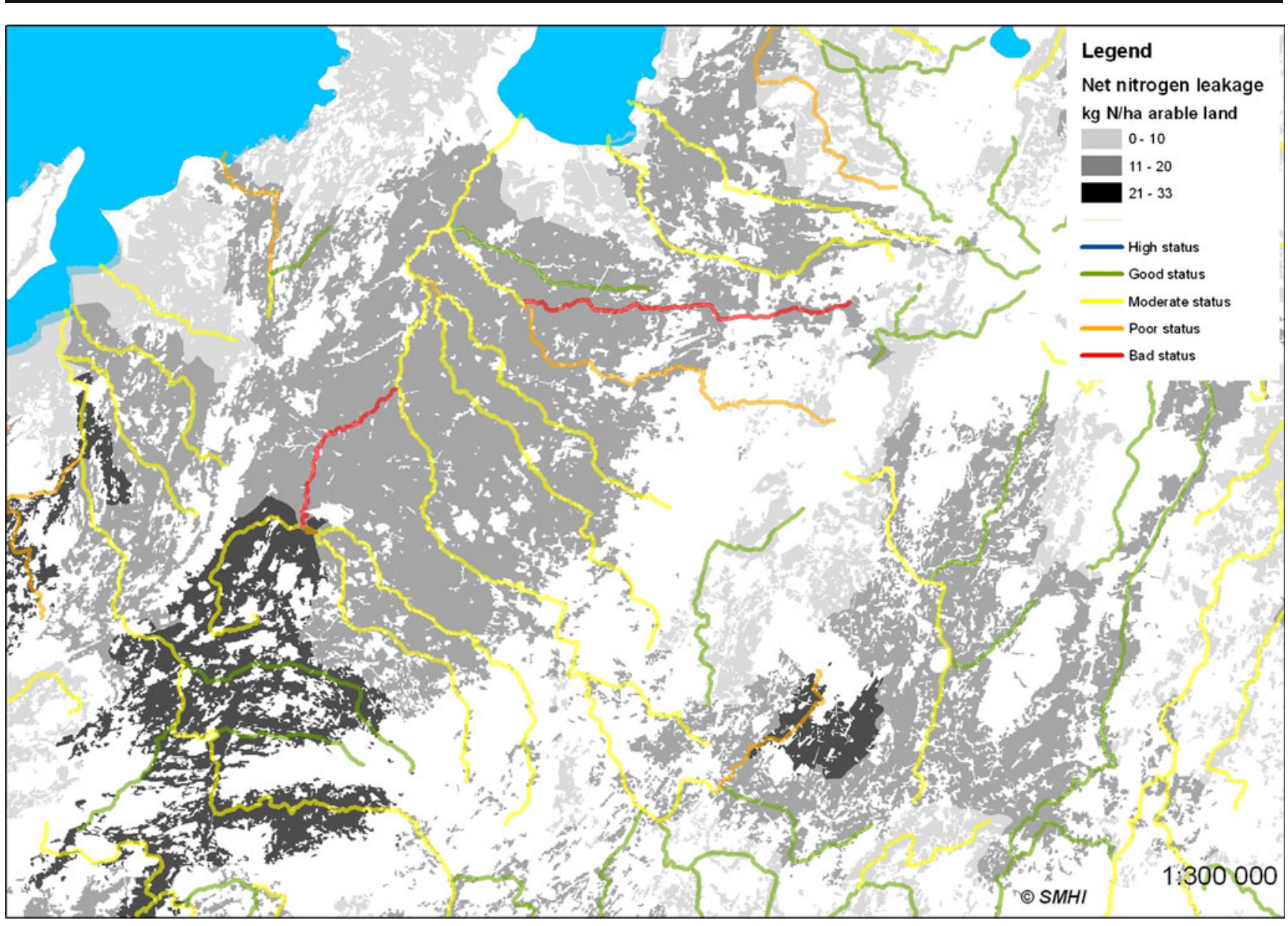

Fig. 3 Combined map of (1) water status in rivers and (2) net nitrogen leakage from arable land, in the Västra Götaland region, Sweden

stakeholders can have a responsibility in ensuring compliance. Given the varying structure of SRC bioenergy supply chains (Fig. 1), it is difficult to suggest stakeholder-specific responsibilities, implying that the RED-associated criteria should be considered by all stakeholders along SRC bioenergy supply chains. In addition, effective consideration of some criteria may require interactions between several stakeholders depending on their respective involvement along the SRC bioenergy supply chain. Providing opportunities for such interactions is important but may be challenging, as experiences from Sweden show that coordination between different stakeholders involved with SRC can be poor [18] (see Fig. 2, fact box). It is important that a sustainability framework is designed so as to facilitate stakeholder interaction to clarify the stakeholders' respective roles and responsibilities and to identify points where conflicts of interests may arise and where there are tradeoffs to be made between partly non-compatible goals and objectives. Proper consideration of all relevant aspects therefore requires all stakeholders in the SRC supply chain to be engaged in the development of SRC production systems and that a landscape perspective is used.
Producer manuals, EIAs, and voluntary certification schemes can all be useful for ensuring that SRC bioenergy is produced with sufficient consideration given to the REDassociated criteria. However, they currently do not suffice for this purpose, either individually or combined. Producer manuals need to be complemented to sufficiently cover the RED-associated criteria (Table 3), and advice on how producers should monitor their activities in order to demonstrate compliance should be provided. EIAs also need to be extended to sufficiently consider all criteria (Table 4), but they also need to be streamlined to become less time consuming and expensive. Regarding voluntary certification schemes, national sustainability frameworks for SRC need to be designed so that the producing stakeholders are well informed about the availability and relevance of certification options, which in most cases is likely to vary between countries. The coverage of certain certification schemes in relation to the RED-associated criteria also needs to be assessed on a country level, although continuously considering outcomes from the EC benchmarking process.

Thus, a sustainability framework for SRC bioenergy can include several components. Most importantly though-a 


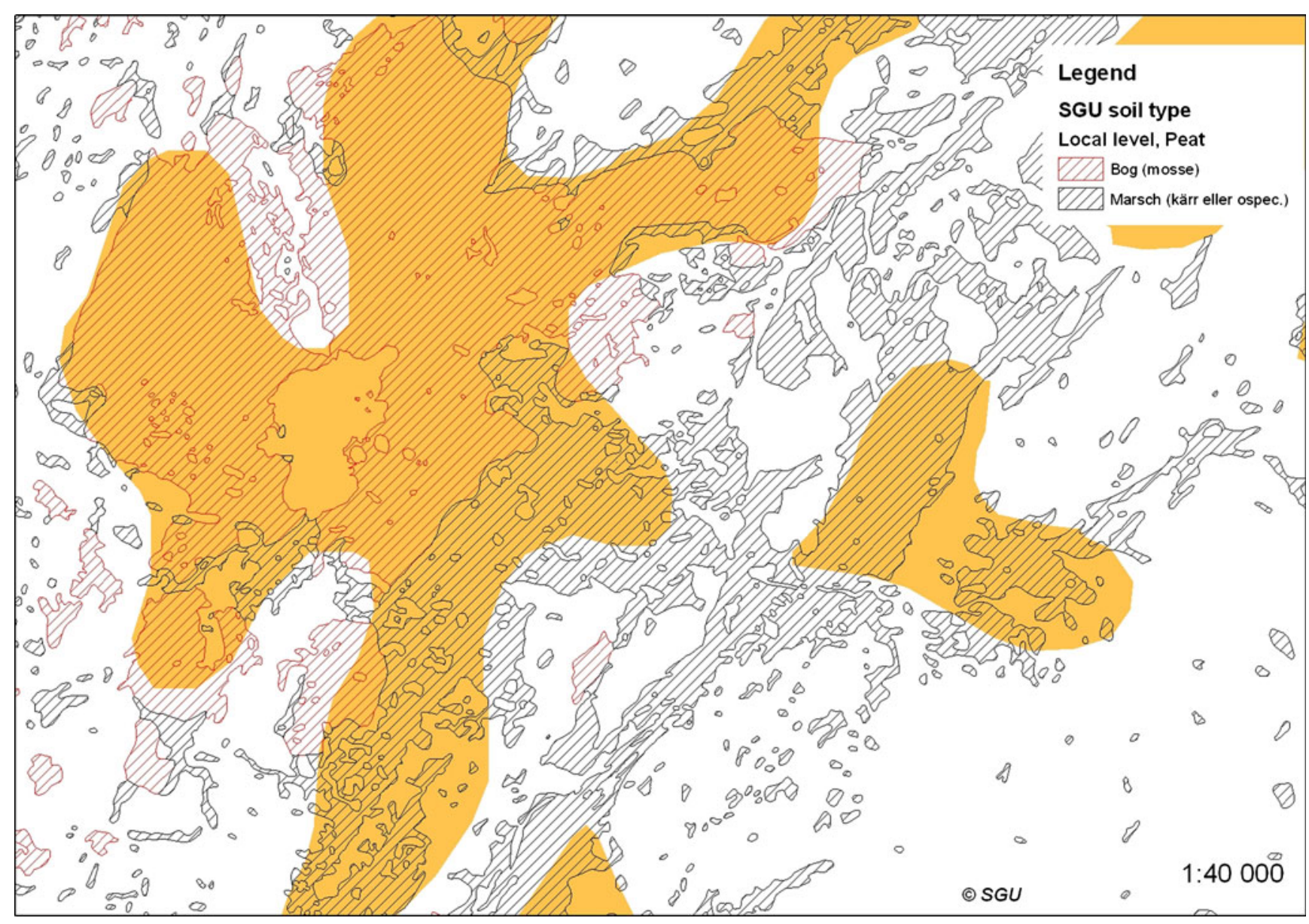

Fig. 4 Overlay of (1) a national soil class layer (peat) with low resolution and (2) a local soil class layer (peat) with high resolution, in an area close to Hornborgarsjön in the Västra Götaland region,
Sweden. The homogenous yellow area shows peatlands according to (1), the area with red stripes shows bogs according to (2) and the area with black stripes shows marches according to (2). sustainability framework needs to provide landscape level processes and engage all involved stakeholders. An appropriate institution should take a formal role in coordination, to ensure that developments are progressing in line with the interests of all stakeholders. From a Swedish perspective, county administrative boards may be best suited for this role since they are already involved in regulating SRC bioenergy stakeholders in different ways. In other countries, similar multi-sectoral administrative authorities involved in planning and governing rural development issues could be appropriate.

Multi-stakeholder, landscape level processes should include initiatives that allow a wide range of stakeholders to engage in dialog on collective issues. In Sweden, a recent initiative, "Salixdagen" (the Salix day), gathered several important stakeholder groups to discuss the potential of $\mathrm{SRC}$ in Sweden. Such initiatives should be realized also on sub-national levels. "Roundtable" sustainability certification initiatives, such as Roundtable on Sustainable Palm Oil and national FSC meetings, are other good examples that can be learnt from.
A Way Forward: Integrated Assessments of Landscape Level and Site-Specific Aspects

Consideration of values linked to biodiversity and cultural heritage, as well as esthetic and other landscape values, requires landscape level analyses. Other more site-specific aspects, such as soil quality, can be treated using suitable indicators. The use of geographic information systems (GIS) can facilitate an integrated assessment of both landscape level aspects and the more sitespecific aspects. This is shown in Fig. 3 where a combined map of nitrogen leakage in cropland and water status in rivers in the Västra Götaland region of Sweden has been produced using GIS technology. Producing maps similar to Fig. 3 may be an appropriate strategy for identifying areas where SRC can be cultivated in compliance with the RED-associated criteria that restrict conversion of certain types of ecosystems/areas. Such maps can later be used by stakeholders in the SRC bioenergy supply chain for proving RED eligibility. In 


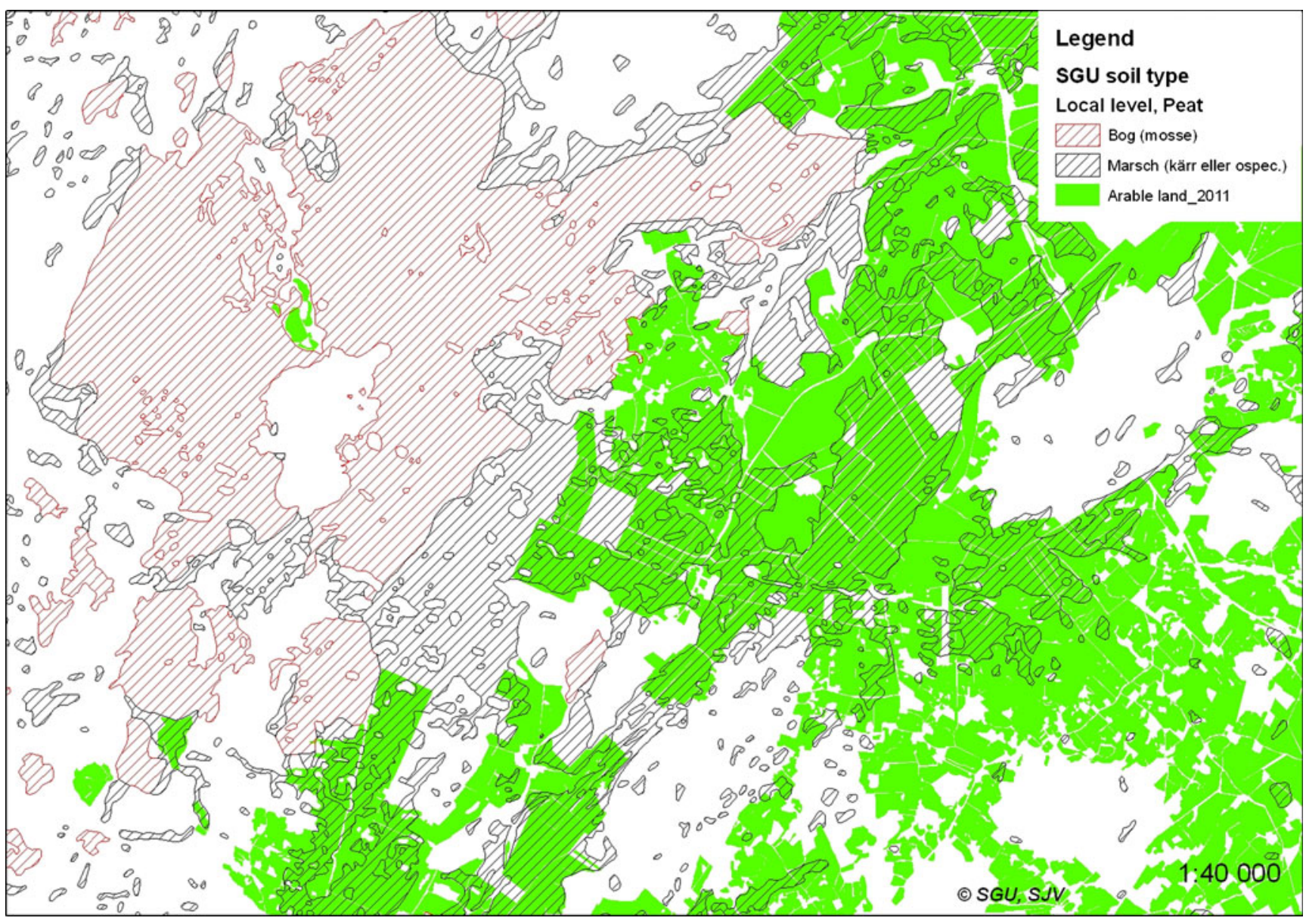

Fig. 5 Overlay of (1) a local-level soil class layer (peat) with high resolution and (2) a local-level land-cover layer (arable land) with high resolution, in an area close to Hornborgarsjön in the Västra Götaland region, Sweden (same area as in Fig. 4)

Sweden, each field of agricultural land has a unique identity, ${ }^{8}$ which theoretically makes it possible to create a database of fields suitable for SRC cultivation with sufficient consideration given to the RED-associated criteria.

Since the baseline year in the RED is $2008,{ }^{9}$ datasets from 2008 or a few years earlier are required for GIS technology to be useful for the purpose described above. It is also important that definitions used in GIS datasets are comparable to definitions laid out in the RED. For example, "continuously forested areas" may be defined differently in a GIS dataset than in the RED, which is likely to cause difficulties if maps based on such datasets are to be used for proving compliance with RED sustainability requirements. It is also important to use datasets with sufficiently high resolution. If a particular field is investigated, a map based on a dataset with low

\footnotetext{
${ }^{8}$ Other EU countries use similar systems.

${ }^{9}$ The status of a particular area in 2008 (e.g., natural forest, wetland etc.) is assessed when the RED-eligibility of a bioenergy project is determined.
}

resolution may not be sufficiently detailed. This is particularly the case where areas "protected" by legally binding RED requirements exist adjacent to an assessed field. This is shown in Fig. 4 where two different soil-type layers are shown, a national layer with low resolution and a local layer with high resolution. It is clear that the two layers do not entirely match. In this case, the national layer may not have a sufficiently high resolution for the map to prove that a particular field has been established on lands other than peatland. In Fig. 5, the local soil-type layer is shown with a layer of arable land (i.e., existing cropland). These layers have a similar resolution and the map may therefore be possible to use for identifying fields located on peat soils, where SRC cultivation should be avoided.

GIS can also be used for supporting the location, design, and management of SRC plantations to produce various environmental services, e.g., reduce nutrient leaching and prevent eutrophication [12, 26, 27], cadmium removal [12, 28], and promoting biodiversity $[14,15]$. Such environmental services may not be explicitly relevant for the RED eligibility of SRC bioenergy, but can nevertheless be important to 
consider when assessing the overall environmental performance of different production systems on a landscape level.

GIS technology may also be a useful tool for developing regional producer manuals, conducting EIAs ${ }^{10}$, or demonstrating compliance to certification standards. It has however been scarcely used for such purposes in the past, much due to the needs of high-resolution datasets, which not always exist, and competent human capital, which can be too costly in case of smaller projects with limited financial capital. A centralized mapping of SRC suitability, as discussed above, may help to mitigate these constraints and thus make GIS more applicable also for these purposes.

Thus, by using GIS technology, administrators may be able to provide other stakeholders in the SRC bioenergy supply chain (particularly landowners, entrepreneurs, and bioenergy producers) with maps or databases over areas/ fields suitable for SRC cultivation, with sufficient consideration given to the RED-associated criteria (see Fig. 5). For example, by combining datasets on soil and land-cover classes, maps, or field databases of no-go areas for SRC production in relation to the required preservation of peatlands and certain ecosystems, can be created - provided that regularly updated datasets of high accuracy and resolution exist and that definitions of land-cover or soil-type classes are comparable to the definitions laid out in the RED. Given that administrators typically regulate the producing stakeholders in different ways, it should also be possible for them to require that such maps or databases are consulted prior to the initiation of new SRC projects.

Acknowledgments The study was financed by the Swedish Energy Agency's project 31455-1 within the frame of ERA-Net Bioenergy, which is gratefully acknowledged. We would also like to thank Mr. Dino for the support and two anonymous reviewers for their valuable comments.

\section{References}

1. IEA (2008) Energy technology perspectives. International Energy Agency. http://www.iea.org/techno/etp/index.asp. Accessed 29 Nov 2011

2. IEA (2010) World energy outlook 2010 edition. International Energy Agency. http://www.iea.org/weo/2010.asp. Accessed 29 Nov 2011

3. IPCC (2011) Special report on renewable energy sources and climate change mitigation (IPCC SRREN). Intergovernmental Panel on Climate Change. http://srren.ipcc-wg3.de/report. Accessed 29 Nov 2011

\footnotetext{
${ }^{10}$ In the Environmental, Social, and Health Impact Assessment for the Addax Bioenergy sugarcane to ethanol project in Bombali, Sierra Leone [29], GIS was used for assessing several impacts. To make the GIS analyses possible, they had to produce high-resolution datasets themselves, as such datasets did not exist for the study area.
}

4. Junginger M, van Dam J, Zarrilli S, Mohammed FA, Marchal D, Faaij A (2010) Opportunities and barriers for international bioenergy trade. Energy Policy 39(4):2028-2042

5. O'Connell D, Braid A, Raison J, Handberg K, Cowie A, Rodriguez L, George B (2009) Sustainable production of bioenergy: a review of global bioenergy sustainability frameworks and assessment systems. Rural Industries Research and Development. https://rirdc.infoservices.com.au/items/09-167. Accessed 29 Nov 2011

6. Stupak I, Lattimore B, Titus BD, Tattersall Smith C (2011) Criteria and indicators for sustainable forest fuel production and harvesting: a review of current standards for sustainable forest management. Biomass Bioenergy 35(8):3287-3308

7. van Dam J, Junginger M, Faaij APC (2010) From the global efforts on certification of bioenergy towards an integrated approach based on sustainable land use planning. Renew Sustain Energy Rev 14 (9):2445-2472

8. European Council (2009) Directive 2009/28/EC of the European Parliament and of the Council of 23 April 2009 on the promotion of the use of energy from renewable sources and amending and subsequently repealing Directives 2001/77/EC and 2003/30/EC. http://eurlex.europa.eu/LexUriServ/LexUriServ.do?uri=OJ:L: 2009:140:0016:0062:en:PDF. Accessed 29 Nov 2011

9. European Commission (2010) Report from the Commission to the Council and the European Parliament on sustainability requirements for the use of solid and gaseous biomass sources in electricity, heating and cooling (SEC(2010) 65 final SEC (2010) 66 final). http://ec.europa.eu/energy/renewables/transparency_platform/doc/2010_report/com_2010_0011_3_report. pdf. Accessed 29 Nov 2011

10. Styles D, Jones M (2007) Energy crops in Ireland: quantifying the potential life-cycle greenhouse gas reductions of energy-crop electricity. Biomass Bioenergy 31(11-12):759-772

11. Dimitriou I, Baum C, Baum S, Busch G, Schulz U, Köhn J et al (2009) The impact of short rotation coppice (SRC) cultivation on the environment. Landbauforschung — vTI Agric For Res 3(59):159-162

12. Dimitriou et al. This Issue

13. Baum C, Leinweber P, Weih M, Lamersdorf N, Dimitriou I (2009) Effects of short rotation coppice with willows and poplar on soil ecology. Landbauforschung 59(3):183-196

14. Baum et al. This Issue

15. Schultz et al. This Issue

16. Council of Europe (200-) The European Landscape Convention. Council of Europe. http://www.coe.int/t/dg4/cultureheritage/heritage/ Landscape/default en.asp. Accessed 29 Nov 2011

17. Englund O, Berndes G, Johnson H, Ostwald M (2011) Environmental Impact Assessments: Suitable for supporting assessments of biofuel sustainability? Technical report for the EU Biofuel 2008 Baseline study. Chalmers University of Technology. http://publica tions.lib.chalmers.se/cpl/record/index.xsql?pubid=146738. Accessed 29 Nov 2011

18. Weih M (2006) Energiskogsodling på åkermark-möjligheter för biologisk mångfald och kulturmiljö i ett landskapsperspektiv. Report to the Swedish Society for Nature Conservation. Swedish University of Agriculture (SLU). http://pub.epsilon.slu.se/3075/1/ SNV_Dnr802-114-04.pdf. Accessed 29 Nov 2011

19. IAIA (1999) Principles of environmental impact assessment best practice. International Association for Impact Assessment. http:// www.iaia.org/publicdocuments/special-publications/Principles\% 20of\%20IA_web.pdf. Accessed 29 Nov 2011

20. IAIA (2010) What is impact assessment? International Association for Impact Assessment. http://www.iaia.org/publicdocuments/ special-publications/What\%20is\%20IA web.pdf. Accessed 29 Nov 2011

21. UNEP (2004) Environmental impact assessment and strategic environmental assessment: towards an integrated approach. The 
United Nations Environment Programme. http://www.unep.ch/etu/ publications/textONUBr.pdf. Accessed 29 Nov 2011

22. European Commission (2011) Memo: certification schemes for biofuels. http://europa.eu/rapid/pressReleasesAction.do?referen ce $=$ MEMO $/ 11 / 522 \&$ format $=$ HTML \&aged $=0 \&$ language $=$ EN\&guiLanguage $=$ en. Accessed 29 Nov 2011

23. EUR-Lex (2011) Case T-278/11: Action brought on 25 May 2011 - ClientEarth and others/Commission. The Publications Office of the European Union. http://eur-lex.europa.eu/LexUr iServ/LexUriServ.do?uri=OJ:C:2011:219:0020:02:EN:HTML. Accessed 29 Nov 2011

24. ClientEarth, Friends of the Earth Europe, Stitching FERN, Corporate Europe Observatory (2011) Application for annulment under article 263 of the treaty on the functioning of the European Union. ClientEarth. http://www.clientearth.org/reports/application-to-court-clientearth-et-al-v-commission-250511.pdf. Accessed 29 Nov 2011
25. FSC Finland (2010) FSC standard for Finland. Finnish FSC Association. http://finland.fsc.org/Dokumentit/FSC\%20Standard\% 20for\%20Finland\%20V1-1\%20APPROVED\%20210111.pdf. Accessed 29 Nov 2011

26. Börjesson P, Berndes G (2006) The prospects for willow plantations for wastewater treatment in Sweden. Biomass Bioenergy 30 (5):428-438

27. Dimitriou I, Rosenqvist H (2011) Sewage sludge and wastewater fertilisation of Short Rotation Coppice (SRC) for increased bioenergy production- biological and economic potential. Biomass Bioenergy 35(2):835-842

28. Berndes G, Fredriksson F, Börjesson P (2004) Cadmium accumulation and Salix based phytoextraction on arable land in Sweden. Agric Ecosyst Environ 103(1):207-223

29. Coastal and Environmental Services (2009) Sugar cane to ethanol project. Draft ESHIA, Sierra Leone 